\title{
Study on Fuzzy Self-adaptive PID for Galvanometer Control System
}

\author{
Shengnan $\mathrm{Li}^{1, \mathrm{a}^{*}}$, Jianzhong $\mathrm{CaO}^{2, \mathrm{~b}}$ and Zuofeng Zhou ${ }^{3, \mathrm{c}}$ \\ ${ }^{1}$ Xi'an Institute of Optics and Precision Mechanics of CAS, Xi'an, 710119, China \\ ${ }^{2}$ Xi'an Institute of Optics and Precision Mechanics of CAS, Xi'an, 710119, China \\ ${ }^{3}$ Xi'an Institute of Optics and Precision Mechanics of CAS, Xi'an, 710119, China \\ alishengnan14@mails.ucas.ac.cn, ${ }^{b}$ caojianzhong@opt.ac.cn, ${ }^{c} z$ houzuofeng@opt.ac.cn
}

\begin{abstract}
Keywords: PID controller. fuzzy self-adaptive control. galvanometer control system.
Abstract. A new method based on fuzzy self-adaptive PID for the galvanometer control system is presented. This method overcomes some defects of the traditional PID control, such as lower control precision and worse anti-jamming performance. At first, this paper analyzed the theory of galvanometer control system and established the mathematical model of the moving magnetic galvanometer motor. Then, the paper presented the design method of fuzzy self-adaptive PID controller in detail and using the simulation software to realize the system design. At last, the simulation results of PID control were compared with those of the Fuzzy-PID control method. The results show that the Fuzzy-PID control method has better dynamic and static performance, as well as anti-jamming performance.
\end{abstract}

\section{Introduction}

In recent years, laser technology has been rapidly developed. And it has been widely used in industrial production. The galvanometer optical scanner is a kind of laser scanning technology developed by General laboratory. Compared with the other scanning scanners, galvanometer optical scanner has the larger scan angle, higher efficiency, higher precision, and more compact structure. From the aspects of the existing scanning performance, it is one of the best laser scanning ways by now [1].

In a complex system, because of the controlled object's time-varying, nonlinear and uncertainty performance, the traditional PID control is always difficult to achieve good control effect. Combining the advanced control strategy with the traditional PID control can be an effective way to solve the problems. People use the method of artificial intelligence which stored in a computer by adjusting the operator's experience as knowledge [2]. Then according to the practical condition, computer will automatically adjust PID parameters. The controller combined the classical PID control with the advanced expert system can be the best control system. The fuzzy theory can be an effective way, because the operator's experience is not easy to accurately describe and the process of the control signals and quantitative evaluation index is not easy to show [3]. At present, there are many kinds of structure forms of fuzzy self-adaptive PID controller, but its working principles are basically the same [4].

\section{The Galvanometer Control System}

Galvanometer Work Mode. The galvanometer is made up of a mirror and a galvanometer. In the application of galvanometer scanner, we generally use two-dimensional laser scanning device, one for the horizontal scanning and the other for vertical scanning [5]. It has many types applied in laser beam positioning motion or command structure. These two types can be classified as random and repeat. A closed-loop galvanometer provides the system designer with high speed and low cost option. These characteristics of galvanometer meet the requirements of a whole variety of applications [6].

Mathematical Model of the Galvanometer Motor. Model of moving magnetic galvanometer motor is shown as Fig.1. 


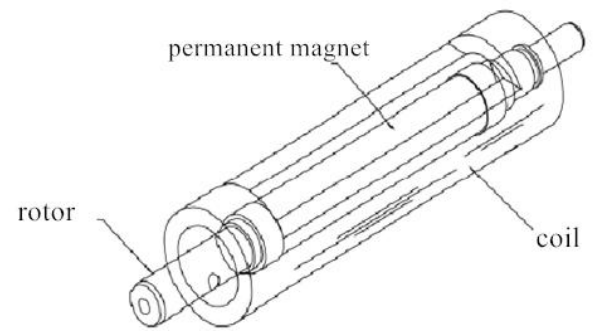

Fig.1 structure of moving magnetic galvanometer motor

The armature balance equation of the galvanometer motor can be defined as Eq. 1 .

$$
\mathrm{u}=\mathrm{L} \frac{\mathrm{di}}{\mathrm{dt}}+\mathrm{Ri}+\mathrm{E}_{\mathrm{b}}
$$

Where $\mathrm{R}$ is the armature resistance of the galvanometer motor, $\mathrm{L}$ is the armature inductance of the galvanometer motor, $E_{b}$ is the back electromotive force of the galvanometer motor, $\mathrm{i}$ is the electric current of the galvanometer motor.

The torque balance equation can be defined as Eq. 2 .

$$
T=J \frac{d^{2} \theta}{d^{2} t}+f \frac{d \theta}{d t}
$$

Where $\mathrm{T}$ is the electromagnetic torque produced by the coil current of thegalvanometer motor, $\mathrm{I}$ is the rotational inertia of the galvanometer motor rotor, $\theta$ is the deflecting angle of the galvanometer motor rotor, $\mathrm{f}$ is the viscous friction coefficient of the galvanometer motor.

Electromagnetic torque of the galvanometer motor can be defined as Eq. 3.

$\mathrm{T}=\mathrm{K}_{\mathrm{T}} \mathrm{i}$.

Where $K_{T}$ is the moment coefficient of the galvanometer motor.

Counter electromotive force of the galvanometer can be defined as Eq. 4.

$\mathrm{E}_{\mathrm{b}}=\mathrm{K}_{\mathrm{b}} \frac{\mathrm{d} \theta}{\mathrm{dt}}$

Where $\mathrm{K}_{\mathrm{b}}$ is the back EMF coefficient of the galvanometer motor.

Mathematical model of the galvanometer motor is shown as Fig. 2

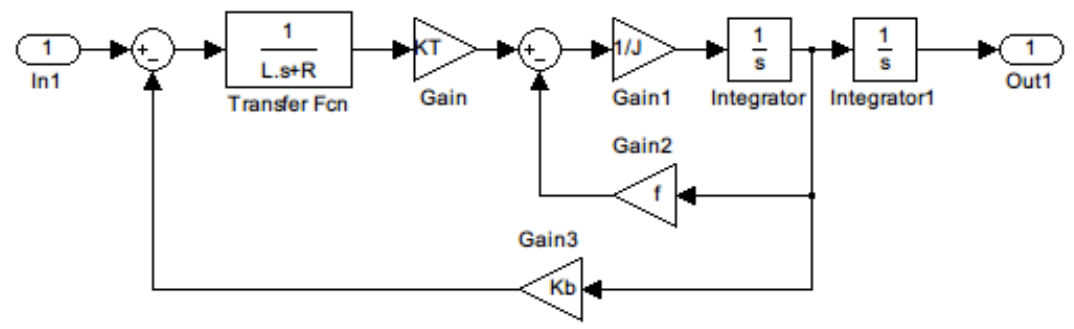

Fig. 2 mathematical model of the galvanometer motor

Then we can get the transfer function of the galvanometer and it can be defined as Eq. 5 .

$\mathrm{G}=\frac{\theta}{\mathrm{U}}=\frac{\mathrm{K}_{\mathrm{T}}}{\mathrm{LJ} \mathrm{s}^{\mathrm{a}}+(\mathrm{Lf}+\mathrm{RJ}) \mathrm{s}^{2}+\left(\mathrm{Rf}+\mathrm{K}_{\mathrm{b}} \mathrm{K}_{\mathrm{T}}\right) \mathrm{s}}$.

Where $\theta$ is the deflection angle of galvanometer, $\mathrm{U}$ is the input voltage of galvanometer coil, $\mathrm{K}_{\mathrm{T}}$ is the moment coefficient of the galvanometer motor, $\mathrm{L}$ is the inductance of the coil, $\mathrm{J}$ is the rotational 
inertia of the coil, $\mathrm{f}$ is the damping constant, $\mathrm{K}_{\mathrm{b}}$ is the back EMF coefficient of the galvanometer motor, $\mathrm{R}$ is the resistance of the coil.

\section{Fuzzy Self-adaptive PID Control Theory}

PID Control Theory. In the simulation control system, the most common control law is PID control. Analog PID control system principle block diagram is shown as Fig.3. The system is composed of analog PID controller and controlled object[7].

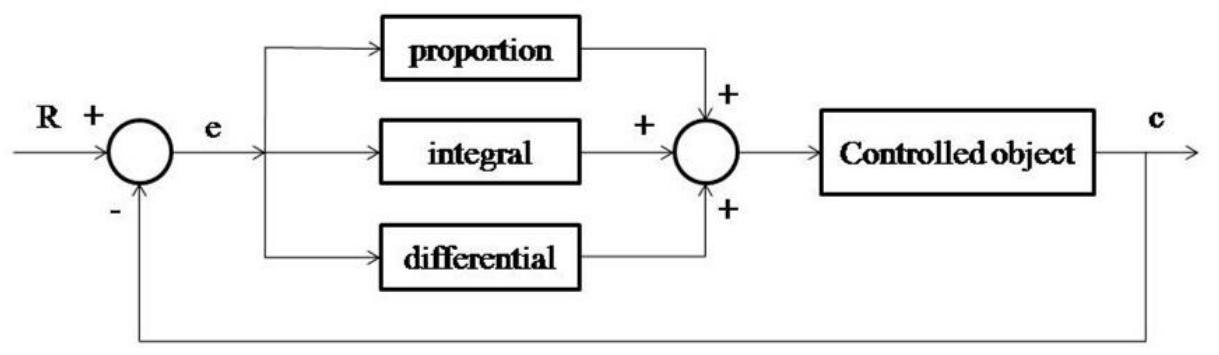

Fig.3 PID model

PID controller is a linear controller, it is according to the given value rin(t) and the actual output values yout $(\mathrm{t})$ constitute the control deviation and it is shown as Eq.6.

$$
\operatorname{error}(\mathrm{t})=\operatorname{rin}(\mathrm{t})-\operatorname{yout}(\mathrm{t})
$$

Control law is shown as Eq.7.

$$
\mathrm{u}(\mathrm{t})=\mathrm{k}_{\mathrm{p}}\left[\operatorname{error}(\mathrm{t})+\frac{1}{\mathrm{~T}_{\mathrm{I}}} \int_{0}^{\mathrm{t}} \operatorname{error}(\mathrm{t}) \mathrm{dt}+\frac{\mathrm{T}_{\mathrm{D}} \text { derror }(\mathrm{t})}{\mathrm{dt}}\right]
$$

Transfer function is shown as Eq.8.

$$
\mathrm{G}(\mathrm{s})=\frac{\mathrm{U}(\mathrm{s})}{\mathrm{E}(\mathrm{s})}=\mathrm{k}_{\mathrm{p}}\left(1+\frac{1}{\mathrm{~T}_{\mathrm{I}} \mathrm{s}}+\mathrm{T}_{\mathrm{D}} \mathrm{s}\right)
$$

Where $k_{p}$ is proportionality coefficient, $T_{I}$ is integral time constant, $T_{D}$ is derivative time constant.

Fuzzy Self-adaptive PID Control Theory. The adaptive fuzzy PID controller uses error e and error changing ec as input.Using the fuzzy control rules modify the PID parameters online, its structure is shown as Fig.4.

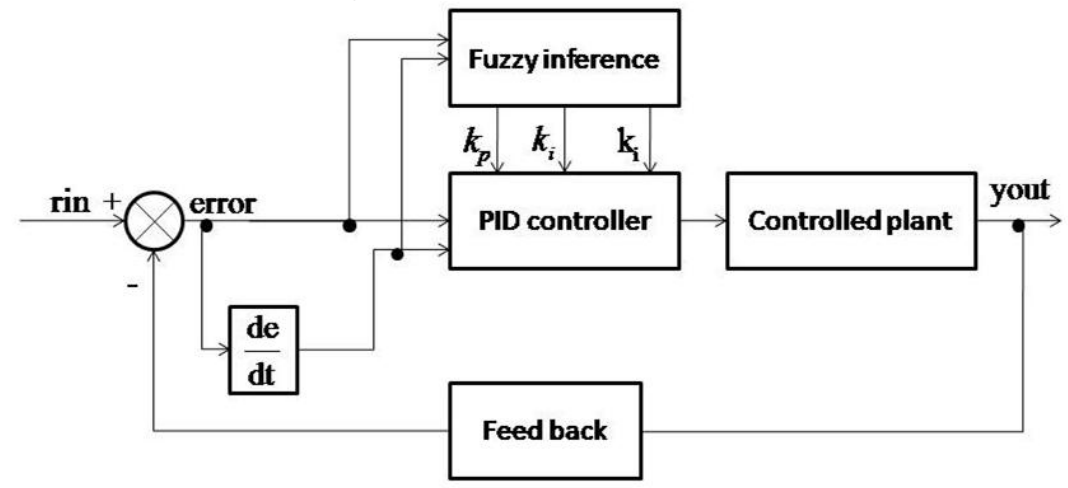

Fig.4 fuzzy PID model

Fuzzy self-tuning of PID parameter is to find out the fuzzy relationship between the three parameters of PID and input parameters (error and error changing). First we should keep testing e and 
ec in operation. Then according to the principle of fuzzy control we modify three parameters online to meet different requirements of the control parameters.

Fuzzy Self-adaptive PID Controller Design. The fuzzy self-tuning PID algorithm is on the basis of traditional PID algorithm. Firstly we calculate the current system error and error change (e and ec). Then we use the fuzzy rules to fuzzy reasoning and query fuzzy matrix table to adjust the parameters.

Defined system error e and error change ec on the fuzzy set theory field, it is shown as Eq.9.

$$
\mathrm{e}, \mathrm{ec}=\{-5,-4,-3,-2,-1,0,1,2,3,4,5\} \text {. }
$$

Fuzzy subset can be defined as Eq. 10.

$$
\text { e, ec }=\{N B, N M, N S, O, P S, P M, P B\} \text {. }
$$

The kernel of the fuzzy controller design is summarizing the engineering designers' technical

\begin{tabular}{|c|c|c|c|c|c|c|c|}
\hline & NB & NM & NS & ZO & PS & PM & PB \\
\hline NB & PB & PB & PM & PM & PS & ZO & 20 \\
\hline NM & PB & PB & PM & PS & PS & 20 & NS \\
\hline NS & PM & PM & PM & PS & 20 & NS & NS \\
\hline ZO & PM & PM & PS & Zo & NS & NM & NM \\
\hline PS & PS & PS & 20 & NS & NS & NM & NM \\
\hline PM & PS & 20 & NS & NM & NM & NM & NB \\
\hline PB & ZO & ZO & NM & NM & NM & NB & NB \\
\hline
\end{tabular}
expertise and establishing proper fuzzy rule tables which is shown in Fig.5.

\begin{tabular}{|c|c|c|c|c|c|c|c|}
\hline & NB & NM & NS & ZO & PS & PM & PB \\
\hline NB & PS & NS & NB & NB & NB & NM & PS \\
\hline NM & PS & NS & NB & $\mathrm{NM}$ & NM & NS & zo \\
\hline NS & 20 & NS & NM & $\mathrm{NM}$ & NS & NS & 20 \\
\hline 20 & $\mathrm{ZO}$ & NS & NS & NS & NS & NS & zo \\
\hline PS & Zo & 20 & zo & 20 & zo & Zo & 20 \\
\hline PM & PB & NS & PS & PS & PS & PS & PB \\
\hline PB & PB & PM & PM & PM & PS & PS & PB \\
\hline
\end{tabular}

\begin{tabular}{|l|l|l|l|l|l|l|l|}
\hline \multicolumn{1}{|r|}{ ec } & \multirow{2}{*}{ NB } & NM & NS & ZO & PS & PM & PB \\
\hline NB & NB & NB & NM & NM & NS & ZO & ZO \\
\hline NM & NB & NB & NM & NS & NS & ZO & ZO \\
\hline NS & NB & NM & NS & NS & ZO & PS & PS \\
\hline ZO & NM & NM & NS & ZO & PS & PM & PM \\
\hline PS & NM & NS & ZO & PS & PS & PM & PB \\
\hline PM & ZO & ZO & PS & PS & PM & PB & PB \\
\hline PB & ZO & ZO & PS & PM & PM & PB & PB \\
\hline
\end{tabular}

Fig.5 fuzzy rule table

Supposing parameters $\left(e, e c, k_{p}, k_{i}, k_{d}\right)$ obeyed normal distribution, we can get the membership degree of fuzzy subsets. According to the membership assignment table of each fuzzy subset and the fuzzy controlling model of each parameter, we can design fuzzy matrix table of PID parameter by using fuzzy synthesis reasoning. Then the PID parameters can be calculated as the Eq. 11 .

$$
\left\{\begin{aligned}
k_{p} & =k_{p}^{0}+\left\{e_{i}, e c_{j}\right\} * q_{p} \\
k_{i} & =k_{i}^{0}+\left\{e_{i}, e c_{j}\right\} * q_{i} . \\
k_{d} & =k_{d}^{0}+\left\{e_{i}, e c_{j}\right\} * q_{d}
\end{aligned}\right.
$$

Where $k_{p}^{0}, k_{i}^{0}$ and $k_{d}^{0}$ are the initial values of the control parameters, $q_{p}, q_{i}$ and $q_{d}$ are corrected parameters of the control system, $\left\{\mathrm{e}_{\mathrm{i}}, \mathrm{ec}_{\mathrm{j}}\right\}$ is the output of the fuzzy rule table.

\section{Simulation and Analysis}

According to the galvanometer mathematic model above, we give some parameter values. The rotor inertia value is $0.97 \times 10^{-7} \mathrm{~kg} \times \mathrm{m}^{2}$. The torque constant value is $1.31 \times 10^{-2} \mathrm{~N} \times \mathrm{m} / \mathrm{A}$. The coil resistance value is $1.07 \Omega$. The coil inductance value is $1.73 \times 10^{-4} \mathrm{H}$. The back electromotive force coefficient value is $2.29 \times 10^{-4} \mathrm{~V} \times s / \circ$. The sampling time is $1 \mathrm{~ms}$. At the 300 th sampling time, we 
give the controller output an interference of 1.0. Fig.6 respectively shows the unit step response curve of conventional PID control and the fuzzy self-adaptive PID control.

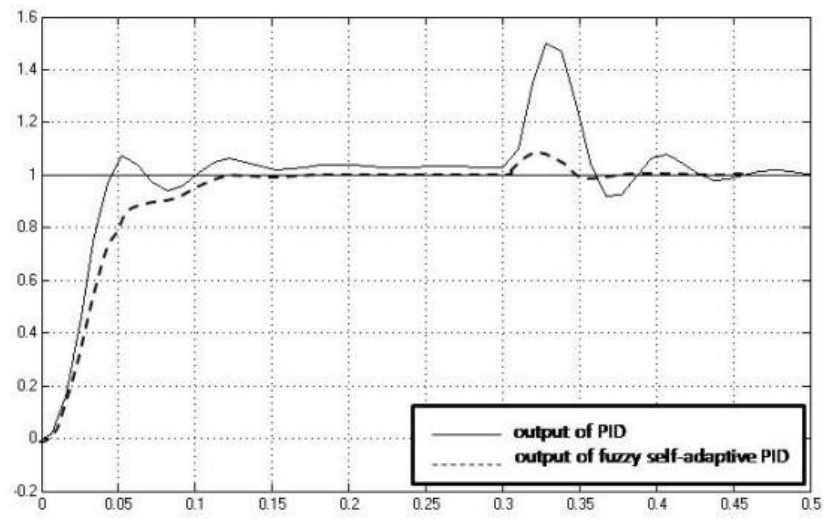

Fig.6 the step response of fuzzy PID control and PID control

From simulation results above, the control method using fuzzy self-adaptive control improves the dynamic performance of the system significantly. We can see that the system response speed is obviously accelerated. We can also clearly see that the fuzzy adaptive controller has strong anti-jamming capability at $0.3 \mathrm{~s}$.

Fig.9 shows the adaptive adjustment of PID parameters.
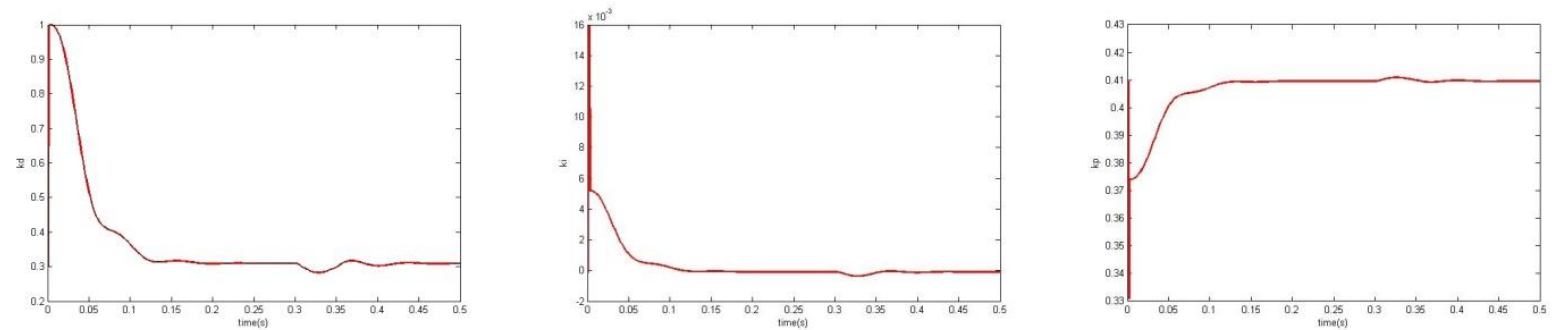

Fig.7 adaptive adjustment of PID parameters

From Fig.7 we can see that all three parameters quickly reach to optimal after $0.1 \mathrm{~s}$ and does not appear fluctuations, the system has good stability. In addition, three parameters can quickly back to optimal when the system suffered interference.

Fig.8 clearly shows the fuzzy PID control system.

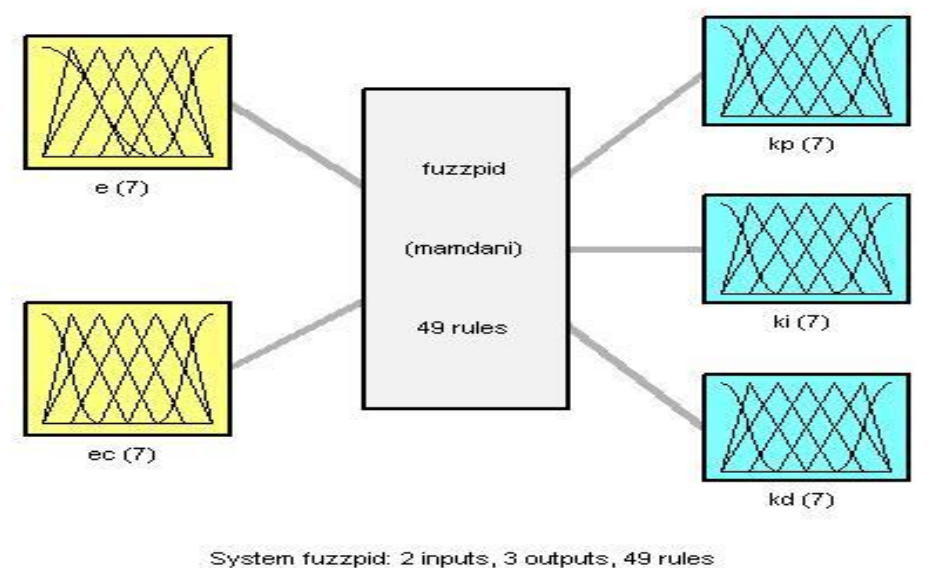

Fig.8 The fuzzy PID control system

\section{Conclusion}

In this paper, a new method based on fuzzy self-adaptive PID for the galvanometer control system is presented. We established the mathematical model of the galvanometer motor and got the transfer function of the vibration mirror. 
From the simulation results, fuzzy self-adaptive PID controller not only has steady state characteristics of the PID controller but also has a faster response time and stronger anti-jamming capability. At the same time, the accuracy also has greatly improved. Its biggest advantage is the system transient time gets shorter with strong anti-interference ability and self-adjusting ability at the higher precision requirement.

\section{References}

[1] Redmond P.Aylwardl, Advanced Galvanometer-based Optical Scanner Design, Sensor Review, Volume 23, Number 3, 2003, 216-222.

[2]J.K. Liu, The Advanced PID Control and Simulation, Beijing, 2004, pp, 115-116.

[3] Y.H. Tao, Y.X. Yin, L.S. Ge, The new method of PID control and its application.1998.

[4] Z.X Sun, Z.D. Deng, Z.C. Zhang, Theory and technology of the intelligent control, 2013, pp, 108-113.

[5] Hwang H.C, Chung C.C, Design of a multi-rate controller and its application to galvanometer servo system. Computer Aided Control System Design, 2001, 564-569.

[6] L.L. Xu, The design of scanning control system based on 2D laser galvanometer, 2012.

[7] X.M. Fan, J.Z. Cao, Optimization of PID parameters based on improved particle-swarm-optimization, ISCC (2013). 